\title{
Particle Emissions of a TDI-Engine with Different Lubrication Oils
}

J. Czerwinski and J.-L. Pétermann University of Applied Sciences, Biel-Bienne A. Ulrich, G. Mueller and A. Wichser 131 ASA 139 EMPA

Reprinted From: General Emissions 2005

(SP-1944)

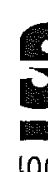




\title{
Particle Emissions of a TDI-Engine with Different Lubrication Oils
}

\author{
J. Czerwinski, J.-L. Pétermann \\ University of Applied Sciences, Biel-Bienne, Switzerland
}

A. Ulrich, G. Mueller, A. Wichser

EMPA, Dübendorf, Switzerland

\section{Abstract}

Due to increasing concern about health effects of fine and ultra-fine particles (nanoparticles) from combustion engines, the diesel particle filter technology (DPF) *) was extensively introduced to heavy duty and passenger cars in the last years. In this respect, a very important parameter is the irreversible plugging of the DPF with non-combustible ashes. The quality of lubrication oil, especially the ash content has a certain influence on regeneration intervals of diesel particle filters.

In the present study, the effects of different lubrication oils on particle mass and nano-particle size distribution were investigated. The test engine $e^{\text {s }}$ was a modern diesel engine without particle filter system.

A main goal was to find out, how different lubrication oils influence the particulate emissions and the contribution of oil to total particle emissions.

Moreover, first results of a tracing study will be discussed. The comparison of a non-doped lubrication oil with a doped oil should enlighten the contribution of the oil to the particle formation.

It will be shown that beside sulphur content the particle emission is also effected by the composition (e.g. additive packages) of the oils.

\footnotetext{
*) Abbreviations \& references see at the end of paper
}

\section{Introduction}

Quality and consumption of lubrication oil was recognized as an important factor for diesel particle filter technology (DPF) in the Swiss activities about retrofitting of construction machines and city busses with DPF systems $[1][2][3][4] *)$. Low ash and low sulphur contents diminish irreversible deposits and increase regeneration intervals of DPF's. However, a main disadvantage is a potential negative effect on oil durability. Therefore, oil exchanges are more often necessary.

Lubrication oil has a significant influence. Thus, the effects of different lubrication oils on particle mass and particle size distribution is of major interest. In previous studies of AFHB concerning VERT verification procedure of DPF's [2][3][6][7][8][9], on a Liebherrengine for construction machines, it was already observed that different lubrication oils provoke different particle emissions. It is known that oil lubricating cylinder walls is a particle source in combustion. Another effect is the blowby, which is recirculated to the intake air of the engine.

Also possible oil losses along the intake valve shafts and in the turbocharger can increase oil consumption.

Therefore further investigation on oil related particle generation are necessary to investigate how different lubrication oils influence the particulate emissions and the amount of oil contribution to total particle emissions. 


\section{Experimental}

Tests were performed with three commercial oils from Lubrizol (GB) within the bus retrofitting projects of city of Biel and Canton Bern which were supported by the Swiss Federal Office of Environment Forests and Landscape (FOEFL). ${ }^{[5]}$ Additionally the effect of three further oils was investigated.

For the tracer study the tests were repeated with two doped lubrication oils containing a mixture of the elements $\mathrm{Pb}, \mathrm{Cd}, \mathrm{Ba}$ and $\mathrm{Sb}$. The oil-based solution was added in a 1:58 ratio to the lubrication oil.

In this study a modern VW TDI $1.9 \mathrm{~L}$ engine was used for the nanoparticle investigations. Fig. 1 shows the engine used in the measuring laboratory with the sampling points and the partial flow dilution tunnel.

\section{Test-Engine}

\section{Engine}

Manufacturer: VW

Type:

Displacement:

Rated RPM:

Rated power:

Model:

Compression ratio:

Oil capacity:

A.JM

$1896 \mathrm{~cm}^{3}$

$4000 \mathrm{rpm}$

$85 \mathrm{~kW}$

4 cylinder $R$

$18: 1$

$4.5 \mathrm{dm}^{3}$.

Combustion process: direct injection Injection pump: unit injectors Supercharging: Turbocharger with vario turbine

Emission control: oxidation catalyst Model year:

1999

\section{Fuel}

Greenergy ultra low sulphur (ULSD) Diesel fuel $(S<10 \mathrm{ppm})$ was used for all tests.

The following standard parameters according to SN EN 590, ${ }^{[10]}$ were used for all tests:
Density (at $\left.15^{\circ} \mathrm{C}\right)$ :
$0.820-0.835 \mathrm{~g} / \mathrm{ml}$
Viscosity $\left(\right.$ at $\left.20^{\circ} \mathrm{C}\right)$ :
Flame point:
Cloud point:
$2.0-4.5 \mathrm{~mm}^{2} / \mathrm{s}$ $\min 60^{\circ} \mathrm{C}$
Filtering limit: $\max =32^{\circ} \mathrm{C}$
Coke residue
CFPP max. $-32^{\circ} \mathrm{C}$
(Conradson at $10 \%$ test residue):
Ash:
$\max .0 .05 \mathrm{~g} / 100 \mathrm{~g}$
Sulphur:
$0,003 \mathrm{~g} / 100 \mathrm{~g}$
Cetane index (determined): $\min .52-54$

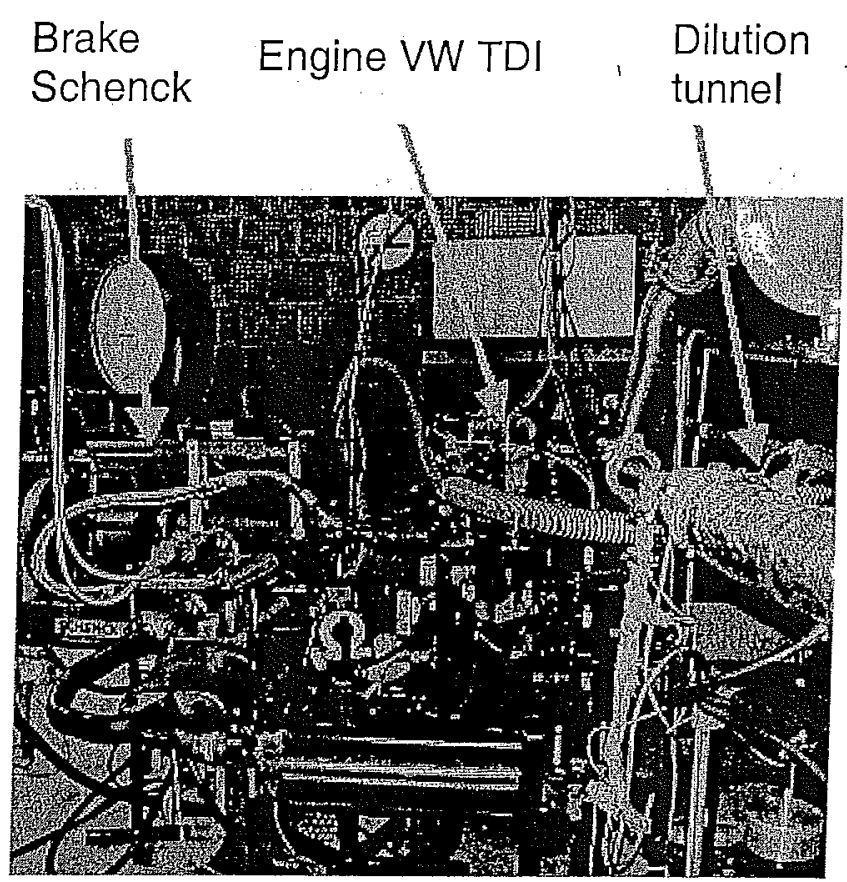

Fig. 1: VW TDI engine at the test stand

\section{Measuring Equipment}

The schematic of measuring set-up is shown in Figure 2.

The following test equipment was used for the measurements of exhaust gas emission:

Volatile components:

- Horiba exhaust gas measurement devices

Type PIR-2000 for $\mathrm{CO}_{2}, \mathrm{CO}, \mathrm{HC}_{\mathrm{IR}}$

- Beckmann Analyzer CLD Model 955 for NO, NOx

- Ratfisch FID RS 5 for $\mathrm{HC}_{\text {FID }}$ 


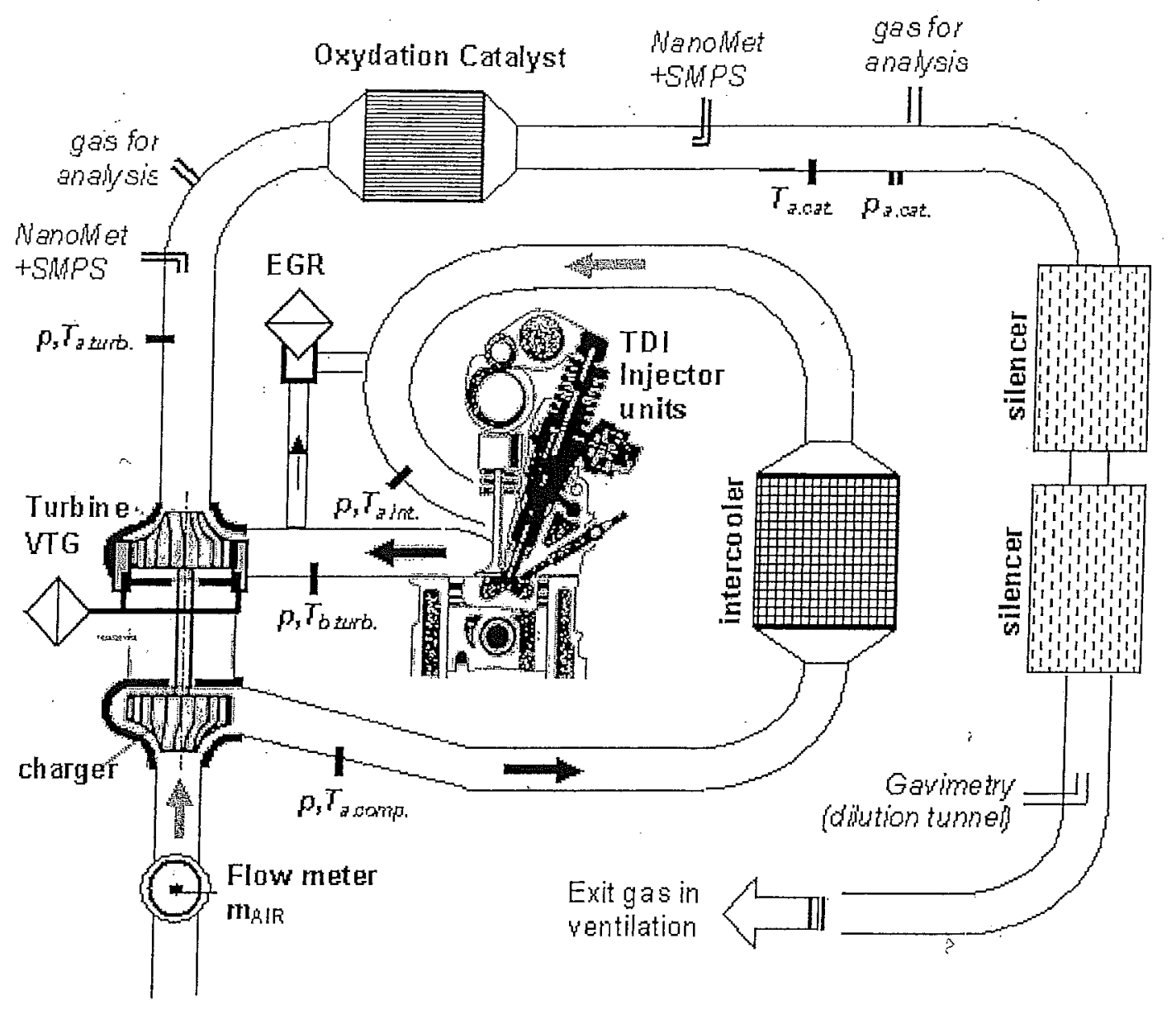

Fig. 2: VW TDI engine measuring set-up

Measurement of particulate mass emissions:

- Sampling and dilution:

partial flow dilution tunnel

Matter-Eng. / METAS

- Gravimetry:

Filter temperature: $\leq 52{ }^{\circ} \mathrm{C}$

accuracy of the scale $\pm 1 \mu \mathrm{g}$

conditioning: $8.24 \mathrm{~h}\left(20^{\circ} \mathrm{C}\right.$, rel.

humidity $50 \%$ )

Particle Counts \& Size Analysis:

As one of the principal objectives of the investigations, the measurements of particle size distributions and count concentrations were performed using:
- SMPS - Scanning Mobility Particle Sizer, TSI (DMA TSI 3071, CPC TSI $3025 \mathrm{~A}$ )

- NanoMet - System consisting of:

PAS - Photoelectric Aerosol

Sensor (Eco Chem PAS 2000)

DC - Diffusion Charging Sensor

(Matter Eng. LQ1-DC)

MD19 tuneable mini-diluter (Matter

Eng: MD19-2E).

The nanoparticles were determined at stationary engine operating conditions, each time before and after oxidation catalyst by switching the hot sampling device of NanoMet. 


\section{Elemental determinations}

Differential elemental analysis was performed at EMPA Inorganic Analytical Laboratory. The emission aerosols sampled on quartz fibre filters (Munktell and Pallflex) were digested in acid mixtures using a 1200 Mega - High Perfomance Microwave Digestion Unit (MSL GmbH). Multiple determinations have been carried out on punched filter segments. A detailed description of the digestion procedure can be found in [10][12][13]. Only suprapure and ultrapure quality acids (Merck) and high-purity water (18.2 MS cm), prepared by a Milli-Q Gradient A10 System (Millipore) were used for sample and standard preparation. Standards were prepared from single and multi-element standards all in ICPquality (Merck and Alfa Aesar). The spectrometers used for determinations of the aqueous digestion solutions were a quadrupole inductively coupled plasma mass spectrometer (q-ICP-MS) ELAN 6000 (Perkin Elmer/Sciex) and a high resolution magnetic sector field ICP-MS ELEMENT II (Thermofinnigan) both operated under standard hot plasma conditions.

Elemental determinations in diesel samples have been performed with a radial inductively plasma optical emission spectrometer (ICP-OES) VistaPro (Varian). Chlorine and sulphur were directly determined using a Philips PW-1400 wavelength dispersive $x$-ray fluorescence spectrometer (WD-XRF).

\section{Procedures of Investigation}

All oils were investigated at steady state warm operation condition of the engine, at 5 operating points, Fig. 3 .
Before change to another oil type the new oil was used to purge the engine without oil filter. The engine was operated for approx. $15 \mathrm{~min}$. With the second definitive new oil filling a new oil filter was applied.

For particle size distribution measurements using SMPS always 3 scans with a total duration of $450 \mathrm{~s}$ were performed. In the same time the NanoMet signals were registered.

The particle sampling time on filters for gravimetry depended on the engine operating point and varied between 10 and $40 \mathrm{~min}$, with the scope to obtain at least $1 \mathrm{mg}$ of particle mass per filter for further analysis:

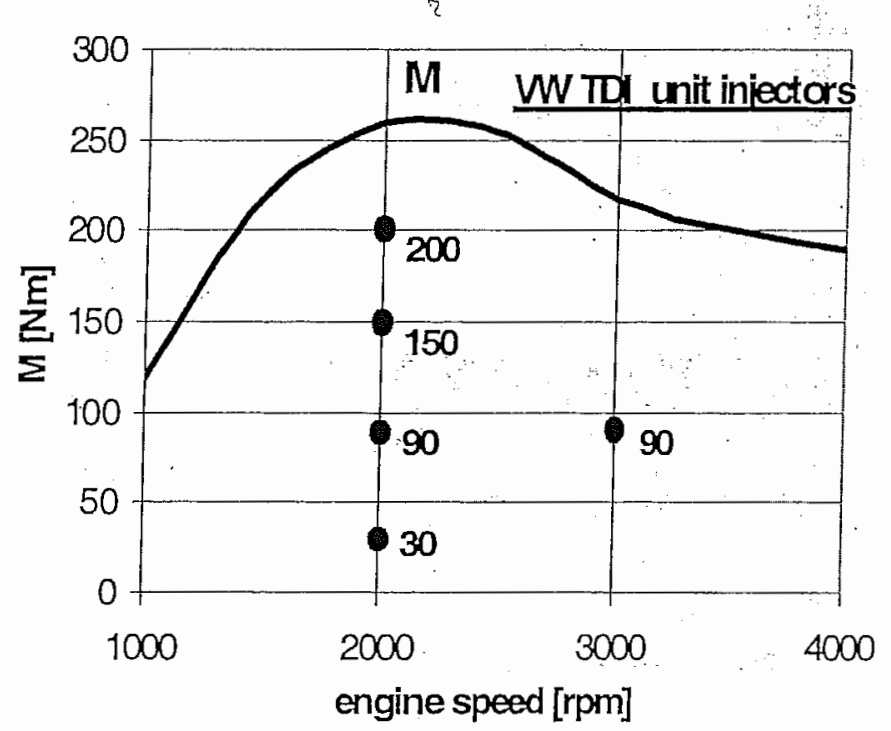

Fig. 3: Engine operating points in the test program

\section{Oils and Tracing}

Oils

The characteristics of the investigated lubrication oils are summarized in Table 1. 


\begin{tabular}{|c|c|c|c|c|}
\hline Property & Unit & 象 & $\frac{9}{9}$ & 0 \\
\hline Viscosity kin $40^{\circ} \mathrm{C}$ & {$\left[\mathrm{mm}^{2} / \mathrm{s}\right]$} & 70.57 & 108.9 & 94.92 \\
\hline Viscosity kin $100^{\circ} \mathrm{C}$ & {$\left[\mathrm{mm}^{2} / \mathrm{s}\right]$} & 11.6 & 14 & 13.45 \\
\hline Viscosity index & {$[-]$} & 159 & 135 & 142 \\
\hline Density @ $15^{\circ} \mathrm{C}$ ou $20^{\circ} \mathrm{C}$ & {$[\mathrm{g} / \mathrm{ml}]$} & 0.8617 & 0.885 & 0,8392 \\
\hline Total Base Number & {$[\mathrm{mg} \mathrm{KOH} / \mathrm{g}]$} & & 11.1 & 0.55 \\
\hline Pourpoint & {$\left[{ }^{\circ} \mathrm{C}\right]$} & -54 & -27 & -54 \\
\hline Sulphated ash & {$[\%]$} & 1.52 & & \\
\hline Sulfur & {$[\%]$} & 0.42 & 0.73 & 0.0005 \\
\hline $\mathrm{Mg}=$ & {$[\%]$} & 0.04 & 0.0422 & \\
\hline $\mathrm{Zn}$ & {$[\%]$} & 0.14 & 0.1572 & \\
\hline $\mathrm{Ca}$ & {$[\%]$} & 0.33 & 0.3655 & \\
\hline P & {$[\%]$} & 0.13 & 0.1433 & \\
\hline Mo & {$[\%]$} & & 0.0116 & \\
\hline
\end{tabular}

The additive packages are a major source of elements, which generate the irreversible ashes in the DPF; ashes consisting mostly of sulphates, phosphates and oxides of $\mathrm{Ca}, \mathrm{Mg}$ and $\mathrm{Zn}{ }^{[14][15]}$.

Lowering the ash content of the lubrication oil without deteriorating the oil characteristics and durability is a difficult balance between the contradictory exigencies, which is a challenge joined with DPF technology.

\begin{tabular}{|c|c|c|c|c|}
\hline Property & Unit & ○昌 & ш & $\underline{\overline{0}} \sum_{i}^{\infty}$ \\
\hline Viscosity kin $40^{\circ} \mathrm{C}$ & {$\left[\mathrm{mm}^{2} / \mathrm{s}\right]$} & 104.8 & - & 69.76 \\
\hline Viscosity kin $100^{\circ} \mathrm{C}$ & {$\left[\mathrm{mm}^{2} / \mathrm{s}\right]$} & 14.22 & 13.98 & 11.8 \\
\hline Viscosity index & {$[-]$} & 139 & - & 166 \\
\hline Density @ $15^{\circ} \mathrm{C}$ ou $20^{\circ} \mathrm{C}$ & {$[\mathrm{g} / \mathrm{ml}]$} & - & - & - \\
\hline Total Base Number & [mg KOH/g] & 13.5 & 8.4 & 5 \\
\hline Sulphated ash & {$[\%]$} & 1.8 & 1.077 & 0.47 \\
\hline Sulfur & {$[\%]$} & 0.65 & 0.336 & 0.2 \\
\hline $\mathrm{Mg}$ & {$[\%]$} & 0.001 & 0.001 & 0.022 \\
\hline $\mathrm{Zn}$ & {$[\%]$} & 0.127 & 0.12 & 0.105 \\
\hline $\mathrm{Ca}$ & [\%] & 0.473 & 0.263 & 0.06 \\
\hline $\mathrm{P}$ & {$[\%]$} & 0.116 & 0.111 & 0.095 \\
\hline
\end{tabular}

\section{Tracer Study}

The tracer study was performed to investigate how much the generation of particles is influenced by the lubrication oil. Two oils, oil D 6500*) 15 W40 and oil F 2000 5W30, with different TBN and different S-content (Tab. 1) were applied. First, the tests were performed with the original oils. Secondly the tests were repeated with the doped oils.

The tracer was dosed with the tracer:oil volume ratio of 1:58. The tracer contained 1250 ppm lead Pb, 1250 ppm cadmium $\mathrm{Cd}, 1250 \mathrm{ppm}$ barium $\mathrm{Ba}$ and

Table 1: Characteristics of the studied lubrication oils

Different packages of additives are used to enable the lubricants to fulfil the various requirements.

Only the synthetic oil $\mathrm{C}$ - was additivefree and could be used in the engine only for some hours. The oil $\mathrm{C}$ is a research oil, which is not commercially available and consists of a mixture of paraffin hydrocarbons between $\mathrm{C} 12$ and $\mathrm{C26.}$

Additives protect the oil (antioxidants, antifoam) as well as the engine (anticorrosive, anti-wear) and control the long-life quality of the oil (detergent, dispersive, viscosity index, etc.).
$1250 \mathrm{ppm}$ antimony Sb. Two elements which tend to form volatile compounds $(\mathrm{Cd}$ and $\mathrm{Sb}$ ) as well as two elements which are known to show no such tendency $(\mathrm{Ba}, \mathrm{Pb})$ were selected. Additionally the omni-presence of the elements in the system (engine, oil, fuel) was taken into account.
*) the used numbers indicate ppm $S$ in the oil




\section{Results}

\section{Catalyst}

Figure 4 illustrates some typical plots of exhaust gas components at constant speed, $2000 \mathrm{rpm}$, with one of the investigated oils:

- $\mathrm{CO}$ is reduced due to the conversion in the oxidation catalyst.

- The reduction of NOx in the catalyst is only the artefact of the cold measurement, where the higher $\mathrm{NO}_{2}$-share after the catalyst is more absorbed in the condensation water provoking more NOx-losses; the hot measurement with a supplementary drying of the sampled probe can by a mayor part solve this problem. This was investigated at AFHB in connection with the VERT certification procedures of DPF systems, [6] [16]. The $\mathrm{NO} / \mathrm{NO}_{2}$ conversion in the oxidation catalyst has been controversially focused in the last years. This conversion is of primary importance for the functionality of certain after-treatment devises, like CRT, SCR, or DPNR, but can cause a higher $\mathrm{NO}_{2}$-emission and a higher toxic exposition.

- PM increases at the lower load, because of the higher EGR-rate, which reaches in maximum approx. $25 \%{ }^{[17]}$.

The catalyst has also an effect on the nanoparticle emission:

- The SMPS particle size distribution spectra show after the catalyst lower count concentrations because of diffusion losses and partial oxidation of the precursor substances of condensates (SOF). A typical, very much repetitive example is given in Fig. 5.

- The NanoMet results, Fig. 6, show a reduction of nanoparticle emission in the catalyst.
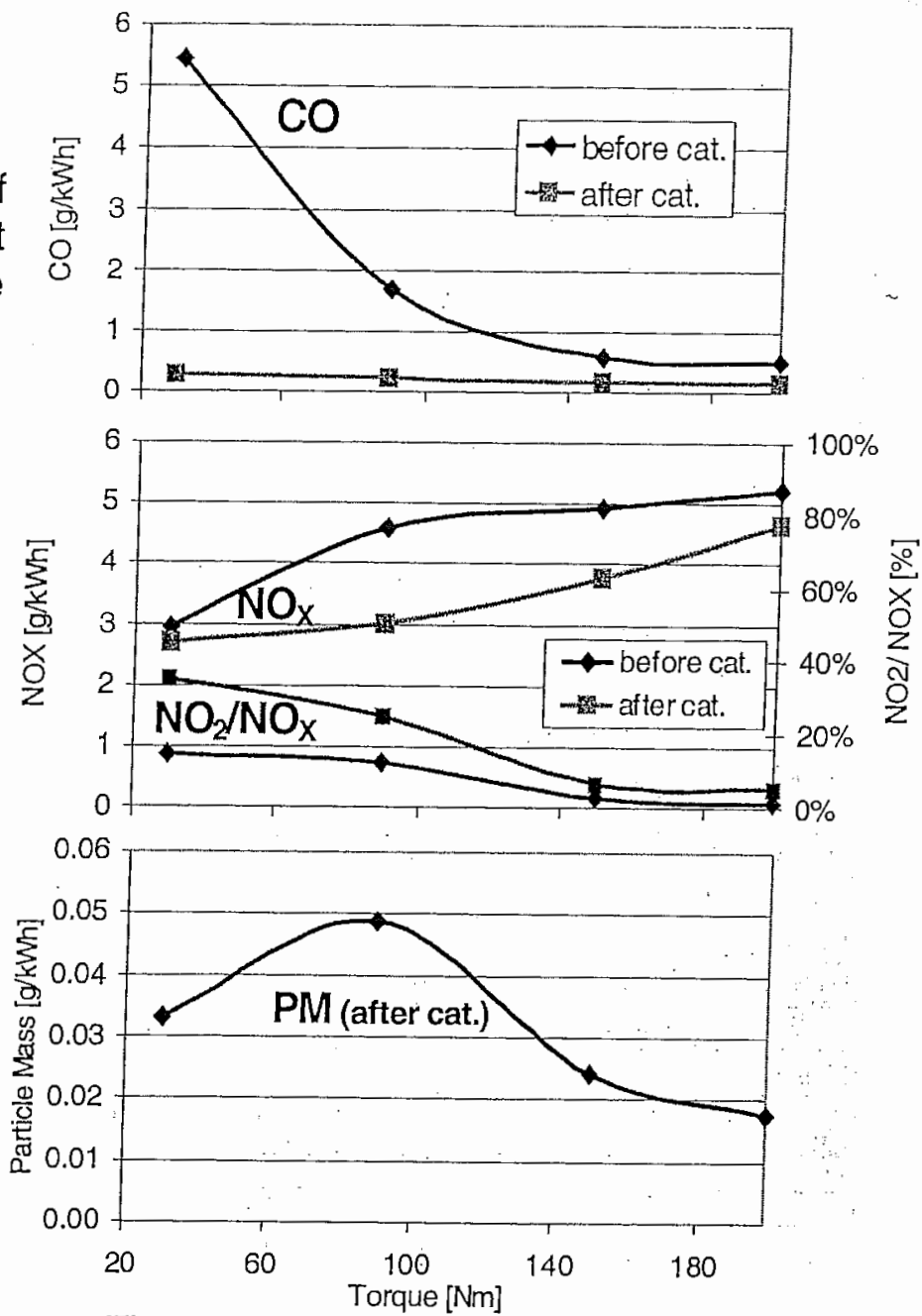

Fig. 4: Emissions and fuel consumption at 2000rpm VW TDI $1896 \mathrm{~cm} 3$, with oil $E 3360$ *)

The signals of PAS and DC in this figure are converted to the values responding to the undiluted volume concentrations in the exhaust gas.

PAS (photoelectric aerosol sensor) is sensitive to the surface of particulates and to the chemical properties of the surface. It indicates the solid particles.

DC (diffusion charging sensor) measures the total particle surface independent of the chemical properties. It indicates the solids and the condensates.

\footnotetext{
*) the used numbers indicate ppm $S$ in the oil
} 


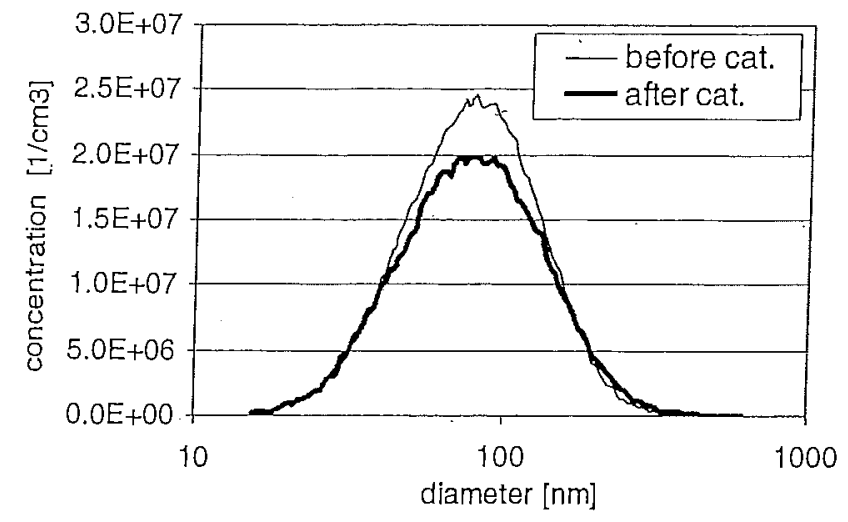

Fig. 5: SMPS particle size distributions before/after catalyst, at 2000rpm VW TDI $1896 \mathrm{~cm} 3$, with oil E 3360

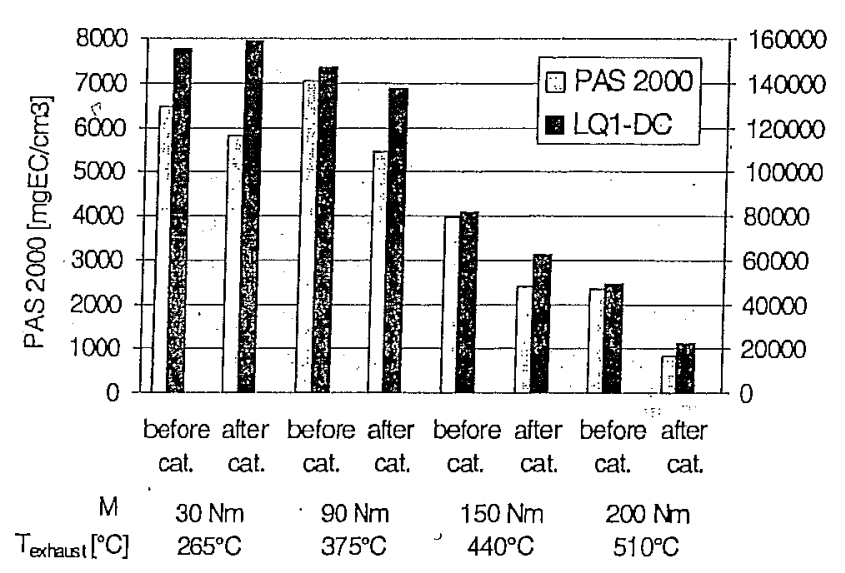

Fig. 6: NanoMet results before/after catalyst, at 2000rpm VW TDI $1896 \mathrm{~cm} 3$, with oil E 3360

Figure 7 represents the reduction rates of nanoparticle counts (SMPS 20 $300 \mathrm{~nm}$ ) and surface (PAS / DC) in the oxidation catalyst with different lubrication oils at the same operating point $3000 \mathrm{rpm} / 90 \mathrm{Nm}$.

In this and in following figures the oils of are listed in the sequence of increasing $\approx 20$ S-content (number ppm).

The reduction rates are in average: for SMPS \& DC between 20 and $25 \%$ and for PAS approx. $35 \%$.

*) the used numbers indicate ppm $S$ in the oil
One of the most important mechanisms is the store-release effect of the particles in the channels of the catalyst due to the diffusion filtration [18][19][20]. A part of the particles in the nanometer size range, adhere on the: walls, agglomerates and can be released afterwards as bigger particles in micrometer range. These effects occur at different time in the different parts of the engine exhaust system [21][22] [23].

Another influence on the nanoparticles originates from the oxidation. On one hand the oxidation of SOF reduces the $\mathrm{HC}$-condensates on the other hand the oxidation of $\mathrm{SO}_{2}$ can increase the sulphate, hydrophilic condensates. The first effect is evidently predominant in the here reported results due to the used sulphur-free fuel.

\section{Lubrication oils}

Figures 8 and 9 represent the nanoparticle and particle mass emissions at different operating points with the different investigated lubrication oils. The oils are sorted in order of decreasing oil sulphur content. All represented parameters (SMPS, PAS, $D C$ and $P M$ ) confirm at all operating conditions that the oils with the lowest S-content increase particle emissions, which is completely opposite to expectations.

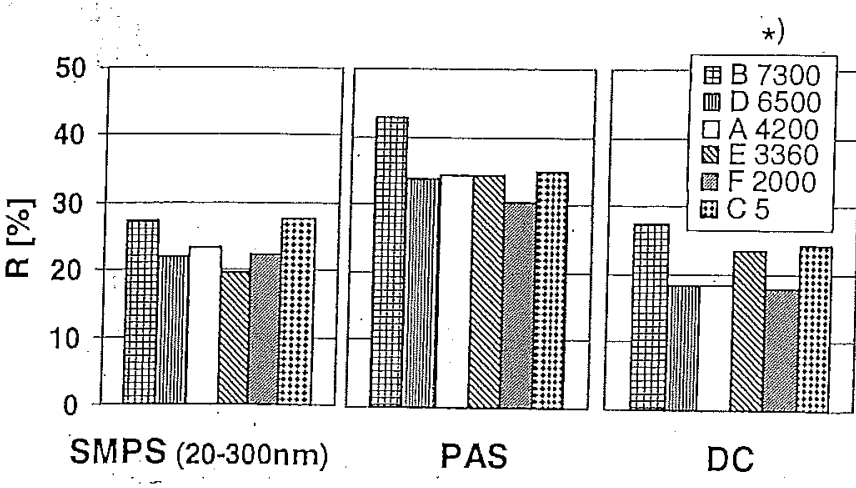

Fig. 7: Reduction rate of nanoparticles $R$ in the catalyst with different lubrication oils (engine at $3000 \mathrm{rpm} / 90 \mathrm{Nm}$ ) 
It can be concluded that the oil composition and the additive packages (except oil C) play an important role in the particle formation.

Regarding back to Fig. 7, it can be remarked that tendentially oils with higher emission values have also higher reduction rates. This is an indication for the fact that the differences of particle emissions for the different lubrication oils are due mostly to the differences of condensates (SOF).
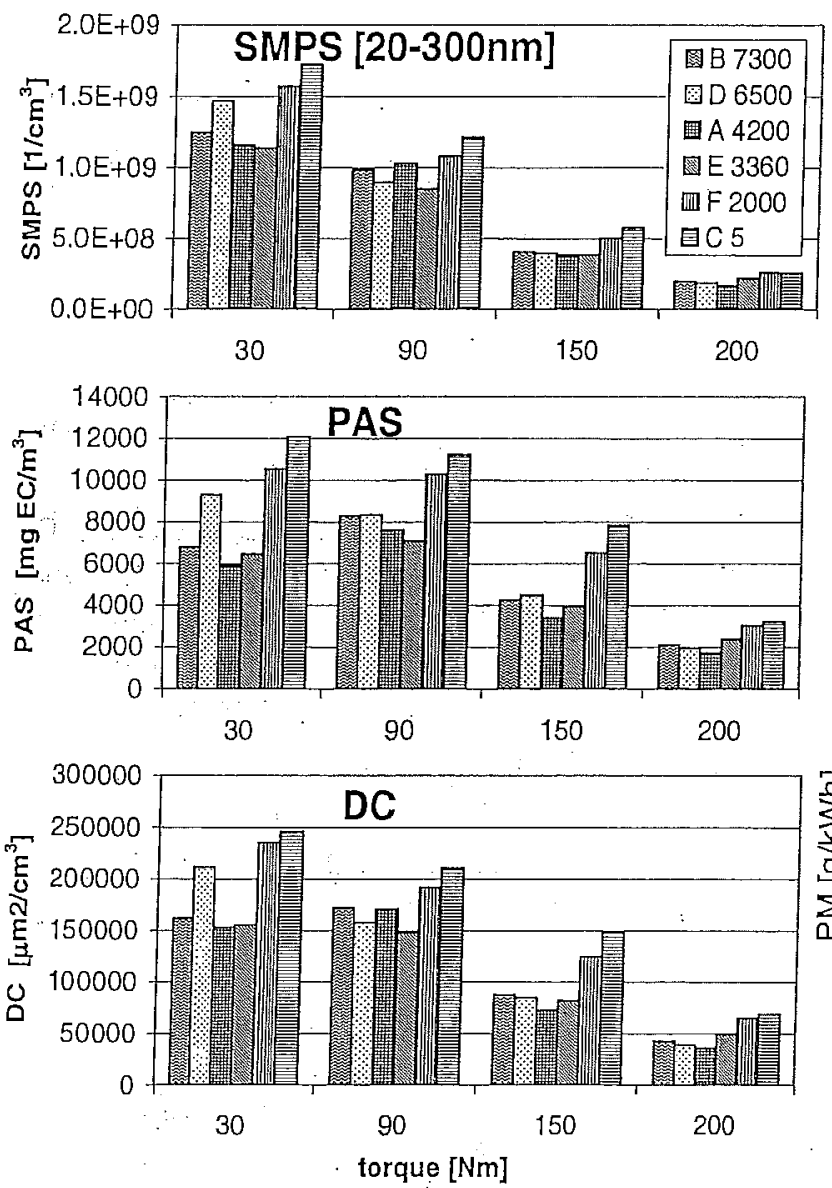

Fig. 8: Nanoparticle emissions with different lubrication oils before catalyst, at 2000rpm

The observed emission differences are certainly an effect of combination of different influences, like:

- Acting of the oil with the piston rings and cylinder wall due to its viscosity.
- Influence of the oil on blow-by flow and blow-by composition.

- Acting of the oil at the cylinder walls during the combustion, oil evaporation, adsorption and desorption of fuel.

- Influence of the oil composition on the particle composition and on the condensation effects (speed of droplets growth).

To clarify all those effects and the possible secondary emissions a considerable further investigations are necessary.

Further investigations are also necessary to confirm the relationships of emissions of different oils at other operating conditions and on other engines. In the single measurements represented here the tendencies are confirmed by different parameters (PM, SMPS, PAS, DC) and by the similarity of these tendencies at all operating points.

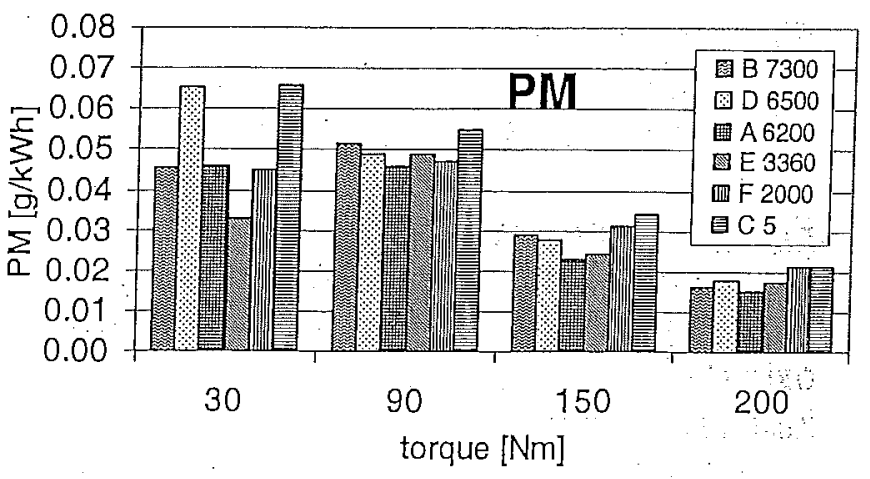

Fig. 9: Particle mass emissions with different lubrication oils at 2000rpm (after catalyst)

These results confirm the higher particle mass and particle counts emissions of this engine, at part load operation, due to increased EGR (see Fig. 4). 


\section{Results of Tracer Study}

The results of the tracer study should enlighten the contribution of lubrication oil on the formation of particulate matter in exhaust emissions. A main goal is an assessment of the lubrication oil contribution for different operation conditions of the engine. First results exemplarily for cadmium with and without tracer are presented in Figure 10. The tests with doped oil showed higher concentrations than the oils without tracer for all operation points. A similar trend was observed for the other elements in the tracer. A correlation between operating condition and the determinable amount of tracer, in the particulate matter is obvious.

The lube oil has a considerable contribution to the PM, particularly at the part load operating conditions of the engine.

Further results will be published later.

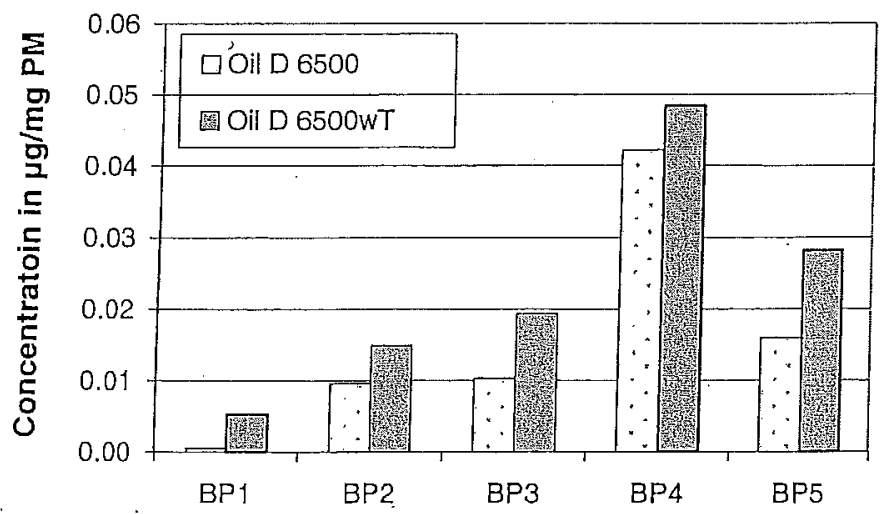

Fig. 10: Cadmium concentration in sampled particle matter for oil D 6500 with and w/o tracer BP 1-5...operating points see Fig. 3

\section{Conclusions}

Following conclusions can be pointed out:

- The oxidation catalyst reduces the nanoparticle emissions due to the diffusion-deposition and oxidation of SOF.

- Reduced sulphur and lower additive content of the lubrication oil don't necessarily reduce the particle emission of the engine.

- The complex influences of oil quality on the particle emissions offer several open questions for further research.

- The results of oil tracing show, that the lube oil has a considerable contribution to the PM, particularly at the part load operating conditions of the engine.

- An increased EGR rate at the part load of this engine provokes also increased emissions of particle mass and counts.

\section{Acknowledgement}

The authors gratefully acknowledge Mr. A. Mayer (TTM Technik Thermische Maschinen) and Dr. N. Heeb, (EMPA) for valuable discussions. We like to thank also A. Maccagnan (EMPA) for preparing the tracer mixtures.

\section{References}

[1] Particulate traps for heavy duty vehicles.

Environmental Documentation No. 130,

Swiss Agency for Environment, Forests and Landscape (SAEFL), Bern 2000

[2] VERT, Final Report, 29.2.2000, Available from SUVA (Swiss National Accident Insurance Organization) Lucerne, www.suva.ch 
[3] Mayer, A.; Czerwinski, J.; Pétermann, J.-L.; Wyser, M.; Legerer, F.: "Reliability of DPFSystems: Experience with 6000 Applications of the Swiss Retrofit Fleet. SAE Paper 2004-01-0076, TTM, AFHB, BUWAL, AKPF.

[4] $7^{\text {th }}$ ETH Conference on Combustion Generated Nanoparticles, www.nanoparticles.ethz.ch

[5] Brun, D.: "Influences de la qualité de l'huile sur les émissions limitées et non limitées du moteur TDI." Travail de diplôme, Moteurs à combustion, Ecole d'Ingénieurs BielBienne, Suisse.

[6] VERT Filter List, tested and approved particle trap systems for retrofitting Diesel engines; www.umwelt-schweiz.ch

[7] Mayer, A.; Heeb, N.; Czerwinski, J.; Wyser, M.: Secondary Emissions from Catalytic Active Particle Filter Systems. SAE Paper 2003-01-0291. TTM, EMPA, AFHB, BUWAL.

[8] Mayer, A.; Czerwinski, J.: VERT Particulate Trap Verification. IX. International Conference "R \& D of Internal Combustion Engines", Vladimir, Russia, May 2729,2003 (ISBN 5-86953-048-2) p. 92 (SAE 2002-01-0435).

[9] Mayer, A.; Ulrich, A.; Czerwinski, J.; Matter, U.; Wyser, M.: Retention of Fuel Borne Catalyst Particles by Diesel Particle Filter Systems. SAE Paper 2003-01-0287, TTM, EMPA, AFHB, ETHZ, BUWAL.

[10] Greenergy Diesel Fuel http://www.greenergy.ch

[11] Ulrich A., Wichser A., Anal. Bioanal. Chem., (2003), Vol. 377, 71-81.

[12]A. Uirich, A. Wichser, Metal analysis of diesel vehicle emissions, Proceedings of 6th ETH Conference on Nanoparticle Measurement, August 2002.

[13]A. Ulrich, A. Wichser, Determination of additive metals in fuel and emissions of diesel vehicles, Proceedings of 7th ETH Conference on Nanoparticle Measurement, August 2003.

[14] Hilzendeger, J.; Rhunke, A; Paehr, G.; Engler, H.-J.: Anforderungsprofil an zukünftige Schmierstoffe für PkWDieselmotoren mit aktiver Abgasnachbehandlung. (VW), VDI-Bericht Nr. 1803, S. 281, Konferenz, Wolfsburg Dez. 2003.

[15] Omeis, J.; Harperscheid, M.; Schuylenburg, $V$ : : Motorenöle im Zielkonflikt zwischen motorischer Performance und geringer Kon-tamination von Abgasnachbehandlungssystemen. (Fuchs Europe GmbH.) FAD Konferenz, Dresden Nov. 2003.
[16] Czerwinski, J.; Napoli, S. et.al.: Kalte und beheizte NOx-Messung, Nafion-Dryer, rbrGerät. Interne Berichte B085/a/b.

Abgasprüfstelle FH Biel, AFHB, Nov. 2000 - Oct. 2003.

[17] Scherrer, D.; Lüthi, Th.: Untersuchungen am VW-TDI Motor. Projektarbeit Verbrennungsmotoren 2002, Abgas-prüfstelle FH Biel, AFHB.

[18] Czerwinski, J.: Partikelemissionen verschiedener Verbrennungs-motoren, Forschungsergebnisse und offene Fragen. Vortragsreihe HDT e.V. Essen, München 45. Juni 2002

[19] Khalek J.-A., Kittelson D., Brear F.: The Influence of Dilution Conditions on Diesel Exhaust Particle Size Distribution Measurement. SAE Technical Paper 199901-1142, University of Minnesota, Perkins Engines Comp.

[20] Lüders H., Krüger M., Stommel P., Lüers B.: The Role of Sampling Conditions in Particle Size Distribution Measurements. SAE Technical Paper 981374, FEV Motorentechnik.

[21] Andrews G.E., Clarke A.J., Rojas N.Y., Gregory D., Sale T.: Particulate Mass Accumulation and Release in Practical Diesel Engine Exhaust Systems under Cold Start Conditions. SAE Technical Paper 2000-01-0508, University of Leeds, Ford Research.

[22] Andrews G.E., Clarke A.J., Rojas N.Y., Gregory D., Sale T.: Diesel Particle Size Distribution Changes at the Exhaust Pipe Outlet During Cold Start in a Passenger Car IDI Diesel with a Practical Exhaust System in Place. SAE Technical Paper 2000-01. 0511, University of Leeds, Ford Research.

[23] Andrews G.E., Clarke A.J., Rojas N.Y., Gregory D., Sale T.: Diesel Particle Size Distribution Changes Along a Practical Exhaust System During Cold Start in Passenger Car IDI Diesel. SAE Technical Paper 2000-01-0514, University of Leeds, Ford Research. 


\section{Abbreviations}

: $\mathrm{AFHB}^{-} \ldots$ Abgasprüfstelle der

Fachhochschule, Biel $\mathrm{CH}$

(Lab. For Exhaust Gas Control, Univ. of Appl. Sciences, Biel-

Bienne, Switzerland)

BUWAL.. Bundesamt für Umwelt, Wald und Landschaft (Swiss EPA, FOEFL, SAEFL)

CO ... carbon monoxide

CRT ... continuously regenerating trap

DC $\quad$... Diffusion Charging sensor

DPF $\quad \ldots$ Diesel Particle Filter

DPNR ... Diesel Particle \& NOx. Reduction

EGR $\quad$... exhaust gas recirculation

EMPA... Swiss Federal Laboratories for Materials Testing and Research

FOEFL... Federal Office for Environment, Forests and Landscape (Swiss EPA, BUWAL)

HC ... Hydrocarbons

INSOF... Insoluble Fraction

NanoMet $\quad$...Thermodiluter + PAS + DC

NOX $\quad$... Nitric oxides $=\mathrm{NO}+\mathrm{NO} 2$

PAS ... Photoelectric Aerosol Sensor

PM $\quad$.. Particulate Matter, Particle Mass

$R \quad \ldots$ reduction rate $R=\Delta x / x b$.cat

SAEFL... Swiss Agency for Environment, Forest and Landscape

SCR ... selective catalytic reduction

SMPS ... Scanning Mobility Particle Sizer

SOF ... Soluble Organic Fraction

TTM ... Technik Termische Maschinen

VERT ... Verminderung der Emissionen von Realmaschinen im Tunnelbau (Swiss - Austrian German project, DPF retrofitting in underground)

VFT $\ldots$ VERT Filter Test 